\title{
Drugs of Abuse and Stress Increase the Expression of GluR1 and NMDAR1 Glutamate Receptor Subunits in the Rat Ventral Tegmental Area: Common Adaptations among Cross-Sensitizing Agents
}

\author{
Lawrence W. Fitzgerald, Jordi Ortiz, Azita G. Hamedani, and Eric J. Nestler \\ Laboratory of Molecular Psychiatry, Departments of Psychiatry and Pharmacology, Yale University School of Medicine, \\ Connecticut Mental Health Center, New Haven, Connecticut 06508
}

Behavioral and electrophysiological evidence suggests that glutamatergic neurotransmission plays an important role in some of the long-term effects of cocaine and other drugs of abuse on brain function. We therefore examined the effect of repeated cocaine treatment on glutamate receptor subunit expression in central dopamine (DA) pathways implicated in many of cocaine's behavioral actions. By immunoblotting procedures using subunit-specific antibodies, we found that repeated, but not acute, cocaine treatment increased the levels of immunoreactivity of GluR1 (an AMPA receptor subunit) and NMDAR1 (an NMDA receptor subunit) in the ventral tegmental area (NTA), a nucleus containing mesolimbic DA neurons. In contrast, chronic cocaine treatment did not alter levels of GluR2 (an AMPA receptor subunit), NMDA2A/B (NMDA receptor subunits), or GluR6/7 (kainate receptor subunits) in this brain region. Moreover, GluR1 and NMDAR1 levels were not regulated in other regions of the mesolimbic or nigrostriatal DA pathways, including the substantia nigra. Because several drugs of abuse and stress can elicit common and cross-sensitizing effects on mesolimbic DA function, we next examined whether repeated morphine and stress treatments would regulate these proteins similarly in the VTA. Although morphine delivered by subcutaneous pellet implantation had no significant effect on subunit levels, morphine delivered intermittently by subcutaneous injections of escalating doses elevated GluR1 levels in the VTA. Repeated restraint stress also increased GluR1 levels in the VTA, whereas an unpredictable stress paradigm (2 stressors/d under variable conditions) increased both GluR1 and NMDAR1 levels in this brain region. Unlike cocaine, morphine, and stress, repeated treatment with other psychotropic drugs (haloperidol, raclopride, sertraline, and desipramine) that lack reinforcing or sensitizing properties did not regulate GluR1 or NMDAR1 subunit levels in the VTA. Increased glutamate receptor subunit expression in the VTA may represent an important molecular mechanism by which drugs of abuse and stress exert common, long-term effects on mesolimbic DA function.

Key words: cocaine; opiates; locomotor sensitization; drug addiction; mesolimbic; dopamine
Although all drugs of abuse are acutely reinforcing, the neural changes that underlie drug addiction (and the associated states of tolerance, sensitization, and dependence) appear to occur gradually over time with repeated drug exposure and persist for a long time after withdrawal. Several lines of evidence indicate that the mesolimbic dopamine (DA) system, which consists of dopaminergic neurons in the ventral tegmental area (VTA) that project to the nucleus accumbens (NAc), prefrontal cortex, and related regions, represents a convergence point at which drugs of abuse with disparate pharmacological properties exert common acute

\footnotetext{
Received June 29, 1995; revised Sept. 1, 1995; accepted Sept. 7, 1995.

This work was supported by USPHS Grants DA07359, DA08227, DA00203 (E.J.N.), and P32-NS07136 (L.W.F.) and the Abraham Ribicoff Research Facilities, Connecticut Mental Health Center, State of Connecticut Department of Menta] Health.

We thank Drs. Stephen Heinemann (The Salk Institute; NMDAR1), Robert Wenthold (National Institutes of Health; GluR1, NMDAR2A/B), John Morrison (Mt. Sinai School of Medicine; GluR2), and Richard Huganir (Johns Hopkins School of Medicine; GluR6/7, KA-2) for providing antibodies against the indicated subunits.

Correspondence should be addressed to Dr. Eric J. Nestler, Department of Psychiatry, Connecticut Mental Health Center, Yale University School of Medicine, 34 Park Street, New Haven, CT 06508.

Dr. Fitzgerald's present address; Du Pont Merck Pharmaceutical Co., Experimental Station, P.O. Box 80400, E400, Wilmington, DE 19880-0400.

Dr. Ortiz's present address: Universite Paris V, Faculte de Pharmacic, Laboratoire de Physinlogie, Paris, France.

Copyright (C) 1995 Society for Neuroscience $0270-6474 / 95 / 160274-09 \$ 05.00 / 0$
}

and chronic effects on brain function (Wise, 1990; Kalivas and Stewart, 1991; Kuhar et al., 1991; Koob, 1992; Fitzgerald and Nestler, 1995; Self and Nestler, 1995).

Acutely, virtually all drugs abused by humans are reported to increase extracellular DA levels in the rat NAc (Di Chiara and Imperato, 1988; Chen et al., 1990). In rats, chronic exposure to most of these drugs can lead to sensitization to their DA-releasing and locomotor-activating properties (Post and Rose, 1976; Robinson et al., 1988; Kalivas and Duffy, 1990; Kalivas and Stewart, 1991). Prominent adaptations in the electrophysiological properties of VTA DA neurons and their targets in the NAc also accompany chronic drug exposure (Henry et al., 1989; Henry and White, 1991; Diana et al., 1993; Shen and Chiodo, 1993). Although the precise molecular mechanisms underlying these functional adaptations are unknown, there is accumulating evidence that regulation of key signaling proteins in the mesolimbic DA pathway (e.g., G-proteins, protein kinases, tyrosine hydroxylase) may play an important role (Striplin and Kalivas, 1992; Sorg et al., 1993; Vrana et al., 1993; Fitzgerald and Nestler, 1995; Self and Nestler, 1995).

Adaptations in DA-related signal transduction pathways, however, are probably only part of the many neurochemical mechanisms involved in the chronic actions of drugs of abuse. Indeed, some evidence suggests a dissociation between changes in me- 
solimbic DA release and locomotor sensitization (Segal and Kuczenski, 1992; Wolf et al., 1994). Glutamate has gained significant attention because of its prominent interaction with central DA function and its reported role in locomotor sensitization (Carlsson and Carlsson, 1990; Kalivas, 1993). Specifically, glutamate receptor antagonists can block the development of locomotor sensitization to stimulants and opiates (Karler et al., 1989, 1991; Schenk et al., 1993; Wolf and Jezioski, 1993) as well as the electrophysiological perturbations in mesolimbic DA function that accompany repeated stimulant exposure (Wolf et al., 1994). Moreover, repeated stimulant exposure recently has been shown to alter the electrophysiological responsiveness of VTA DA neurons and NAC neurons to glutamate (White et al., 1995).

Glutamate could regulate the mesolimbic DA system via several types of receptors, which include the ionotropic NMDA, AMPA, and kainate receptor subtypes (Monaghan et al., 1989; Johnson et al., 1992; Kalivas, 1993; Wang and French, 1993a; Seutin et al., 1994). In the VTA, electrophysiological studies have found a predominant role of NMDA receptors at low glutamate concentrations and of non-NMD $\Lambda$ receptors at higher concentrations (Wang and French, 1993b). Each of these ionotropic glutamate receptors is an oligomer of individually encoded subunits that combine to form receptors with distinct ligand-binding, electrophysiological, and regulatory properties (for review, see $\mathrm{Na}$ kanishi, 1992; Hollmann and Heinemann, 1994). NMDA receptors are voltage-sensitive, cationic ionophores composed of NMDAR1 and NMDAR2A-D subunits. AMPA and kainate receptors mediate voltage-independent synaptic responses and are composed of GluR1-4 subunits and GluR5-7 and KA1-2 subunits, respectively.

Although the role of glutamate receptors in mediating various forms of neural plasticity (e.g., learning and memory, neural ontogeny) is well documented (for review, see Collingridge and Singer, 1990), their contribution to the neural plasticity that purportedly underlies drug addiction or locomotor sensitization is less clear. In the present study, we examined the regulation of individual glutamate receptor subunit proteins in central DA systems after repeated exposure to cocaine and morphine. We also examined regulation of glutamate receptor subunits by repeated stress, because stress and drugs of abuse can exhibit converging neurochemical and behavioral effects at the level of the mesolimbic DA system (see Discussion). Toward these aims, we used antibodies against glutamate receptor subunits which, unlike radioligand-binding techniques, permits an examination of individual subunit regulation within discrete brain regions (Trevisan et al., 1994; Fitzgerald et al., 1995).

\section{MATERIALS AND METHODS}

Drug and stress treatments. Male Sprague-Dawley rats (initial weights 200-250 gm; CAMM) werc group-housed 3-4 per cage under a $12 \mathrm{hr}$ light/dark cycle (lights on at 7 A.M.) and permitted food and water ad libitum. Different groups of rats received repeated treatments of cocaine (NIDA, Bethesda, MD), morphine (NIDA), haloperidol (Sigma, St. Louis, MO), raclopride (Astra, Pleasanton, CA), desipramine (Sigma), or sertraline (Pfizer, Chicago, IL). Each drug group was matched appropriately to its own control group.

Cocaine was administered twice daily $(15 \mathrm{mg} / \mathrm{kg}$, i.p.) for $14 \mathrm{~d}$ or once daily ( $20 \mathrm{mg} / \mathrm{kg}$, i.p.) for 1 or $7 \mathrm{~d}$. Similar paradigms have been shown to produce behavioral sensitization as well as electrophysiological and neurochemical alterations in mesolimbic DA neurons (Henry et al., 1989; Nestler et al., 1993; Fitzgerald and Nestler, 1995). Morphine was delivered under light halothane anesthesia as daily subcutaneous pellets (containing $75 \mathrm{mg}$ of morphine base) for $5 \mathrm{~d}$ or injected twice daily for 10 $\mathrm{d}$ using an escalating dosing paradigm (days 1 and $2,10 \mathrm{mg} / \mathrm{kg}$; days 3 and $4,20 \mathrm{mg} / \mathrm{kg}$; days 5 and $6,40 \mathrm{mg} / \mathrm{kg}$; days 7 and $8,80 \mathrm{mg} / \mathrm{kg}$; days 9 and
$10,120 \mathrm{mg} / \mathrm{kg}$ morphine sulfate, s.c.). Sham-operated rats served as controls for the $5 \mathrm{~d}$ pellet study, whereas control rats for the $10 \mathrm{~d}$ study were injected with $0.9 \%$ saline. The pellet paradigm has been shown to induce states of opioid tolerance and dependence (Blasig et al., 1973; Aghajanian, 1978; Rasmussen et al., 1990), whereas the injection regimen has been shown to produce sensitized behavioral and neurochemical responses to subsequent morphine challenge (Acquas and Di Chiara, 1992; Spanagel et al., 1993). Desipramine (15 mg/kg, i.p.) and sertraline (10 $\mathrm{mg} / \mathrm{kg}$, i.p.), selective reuptake inhibitors of norepinephrine and serotonin, respectively, were administered once daily for $7 \mathrm{~d}$. These doses are based on substantial neurochemical literature (Morinobu et al., 1995). The antipsychotic drug haloperidol was delivered systemically (1 $\mathrm{mg} / \mathrm{kg}$, i.p.) once daily for $7 \mathrm{~d}$ or as needed $\left(0.5 \mathrm{mg} \cdot \mathrm{kg}^{-1} \cdot \mathrm{d}^{-1}\right)$ in the drinking water for $21 \mathrm{~d}$ (Fitzgerald et al., 1995). Controls for the $7 \mathrm{~d}$ haloperidol experiment were injected with $\mathrm{pH}$-matched $0.9 \%$ saline. Controls for the oral $(21 \mathrm{~d})$ haloperidol experiment received normal tap water that was $\mathrm{pH}$-adjusted with dilute acetic acid, final $\mathrm{pH} 6.4$. The oral paradigm has been shown previously to produce depolarization inactivation of dopaminergic neurons in the VTA and substantia nigra (Chiodo and Bunney, 1983). For comparative purposes, another antipsychotic drug, raclopride, was administered for a longer period ( $34 \mathrm{~d}, 2.2$ $\mathrm{mg} \cdot \mathrm{kg}^{-1} \cdot \mathrm{d}^{-1}$ ) in the drinking water, as described previously (Fitzgerald et al., 1995). Controls for the raclopride group received normal tap water. Rats that received injection regimens were killed 16-18 hr after their last injection, whereas those that received oral treatments were killed without withdrawal.

Restraint stress (using commercial decapitation bags) was administered for 45 min daily for $10 \mathrm{~d}$, a paradigm that has been shown to elicit acutely hallmark biochemical responses (e.g., c-fos induction) (Morinobu et al., 1995). Animals were used 16-18 hr after the last treatment. Another group of rats was subjected to an unpredictable stress paradigm for $10 \mathrm{~d}$, during which rats were exposed to several types of stressors that varied each day. The following paradigm, adapted from previous reports (Sapolsky et al., 1984; Willner, 1984, 1991), was used:

Day 1: 12 P.M., cage rotation $(50 \mathrm{~min}) ; 1$ P.M., swim stress $\left(22^{\circ} \mathrm{C}\right)(4$ $\min$ )

Day 2: 11 A.M., cold $\left(4^{\circ} \mathrm{C}\right)$ isolation $(60 \mathrm{~min})$; 7 P.M., lights on (overnight)

Day 3: 12 P.M., lights off (3 hr); 3 P.M., cold isolation (15 min)

Day 4: 6 P.M., cage rotation (50 $\mathrm{min})$; 7 P.M., food/water deprivation (overnight)

Day 5: 1 P.M., swim stress (3 min); 7 P.M., single (isolation) housing (overnight)

Day 6: 11 A.M., restraint stress (60 min); 3 P.M., lights off (2 hr)

Day 7: 10 A.M., swim stress (4 min); 4 P.M., restraint stress (60 min)

Day 8: 7 P.M., isolation housing (overnight); 7 P.M., food/water deprivation (overnight)

Day 9: 10 A.M., cage rotation (20 min); 7 P.M., lights on (overnight) Day 10: 7 P.M., isolation housing (overnight); 7 P.M., food/water deprivation (overnight)

Day 11: 10 A.M., animals killed

Western blot analyses. Brains were removed rapidly from decapitated rats and chilled in ice-cold buffer containing (in $\mathrm{mM}$ ): $126 \mathrm{NaCl}, 5 \mathrm{KCl}$, $1.25 \mathrm{NaH}_{2} \mathrm{PO}_{4}, 25 \mathrm{NaHCO}_{3}, 2 \mathrm{CaCl}_{2}, 2 \mathrm{MgCl}_{2}$, and 10 D-glucose, $\mathrm{pH}$ 7.4. Bilateral tissue samples were isolated by gross dissection or punched from coronal tissue slices, as described previously (Terwilliger et al., 1991; Fitzgerald et al., 1995). Specifically, the VTA and substantia nigra were obtained from coronal brain slices $[-4.8$ to -5.8 relative to bregma (Paxinos and Watson, 1986)] with a 15 gauge syringe needle. To ensure dissociation between the VTA and substantia nigra, the substantia nigra dissections did not include medial aspects of this region. In all experiments, brain regions from individual rats were analyzed separately. Brain samples were homogenized in $1 \%$ SDS. Protein deterninations were made using the method of Lowry. Samples $(15-50 \mu \mathrm{g}$ of protein) were subjected to SDS-polyacrylamide gel electrophoresis, transferred to nitrocellulose membranes electrophoretically, and probed for glutamate receptor subunit levels, as described previously (Fitzgerald et al., 1995). Briefly, the NMDAR1 subunit $\left(M_{x} 116 \mathrm{kDa}\right)$ was immunolabeled using a mouse monoclonal antibody (mAb 54.1; diluted 1:5000) that was raised against a bacterial trpE fusion protein corresponding to NMDAR1 residues $660-811$, a region that represents a putative intracellular loop between transmembrane regions III and IV (Siegel et al., 1994). The GluR2 subunit $\left(M_{\mathrm{r}} 108 \mathrm{kDa}\right)$ was immunolabeled using a monoclonal antibody (mAb 3A11; diluted 1:2000) that was generated against a fusion protein from the N-terminal, putative extracellular domain of GluR2 


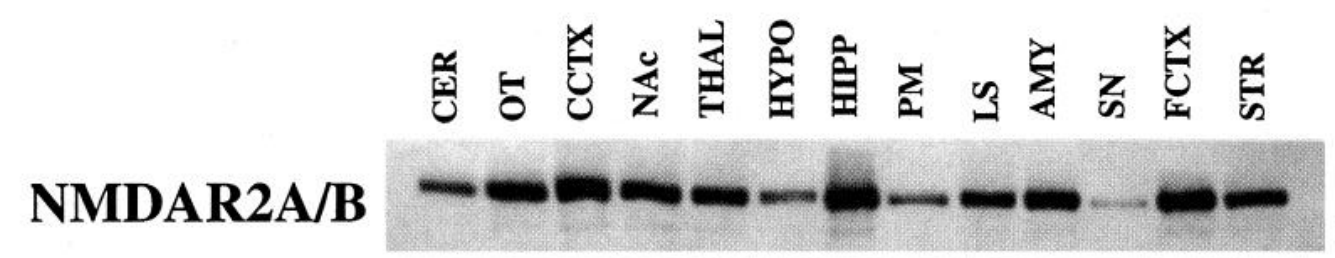

GluR6/7

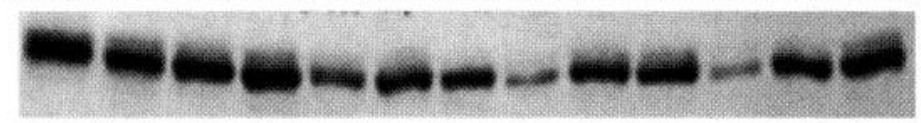

KA-2

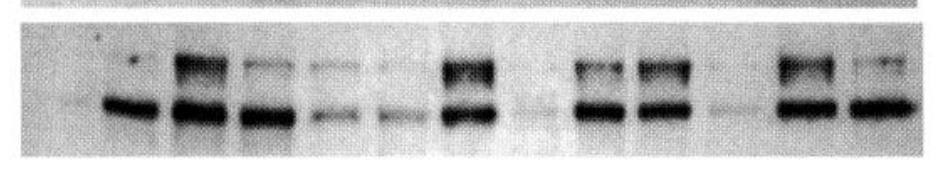

Figure 1. Regional distribution of GluR6/7, NMDAR2A/B, and KA-2 subunits in rat brain. Aliquots (containing 50 $\mu \mathrm{g}$ of protein) of crude SDS extracts were subjected to SDS polyacrylamide gel electrophoresis (SDS-PAGE) and to immunoblotting for $(A)$ GluR6/7 (116 kDa), (B) NMDAR2A/B (150 kDa), and $(C)$ KA-2 (130-150 kDa) subunit protein, as described in Materials and Methods. Similar distribution patterns were observed in the two naive rats analyzed. $C E R$, cerebellum; $O T$, olfactory tubercle; $C C T X$, cingulate cortex; $N A c$, nucleus accumbens; THAL, thalamus; HYPO, hypothalamus; HIPP, hippocampus; $P M$, pons/medulla; $L S$, lateral septum; $A M Y$, amygdala; $S N$, substantia nigra; $F C T X$, frontal/parietal cortex; STR, striatum.
(Puchalski et al., 1994). The GluR1 $\left(M_{\mathrm{r}} 108 \mathrm{kDa}\right)$, GluR6/7 $\left(M_{\mathrm{r}} 116 \mathrm{kDa}\right)$, and NMDA2A/B $\left(M_{\mathrm{r}} 150 \mathrm{kDa}\right)$ subunits were immunolabeled with affinity-purified polyclonal antisera that were generated against $\mathrm{C}$-terminal peptides (Wenthold et al., 1992; Petralia et al., 1994; Roche et al., 1994). The subunit specificity of these antibodies has been established previously. The KA-2 subunit $\left(M_{\mathrm{r}} 130-150 \mathrm{kDa}\right)$ was immunolabeled with a specific polyclonal antiserum (R. Huganir, personal communication). Its specificity was confirmed in the present study by preabsorbing the antiserum with KA-2 antigen peptide (data not shown). Proteins were detected using horseradish peroxidase-conjugated IgG (diluted 1:2000; Vector, Burlingame, CA) followed by chemiluminescence (DuPont NEN, Boston, MA). Uniform transfer of proteins was confirmed on selected blots by staining with amido black (Sigma). Levels of immunoreactivity were quantitated using computer-assisted densitometry (LKB Ultrascan) and were linear over at least a threefold range of tissue concentration. Optical density values were analyzed by Student's unpaired $t$ tests and then expressed as mean percent of control values $( \pm$ SEM) for graphic clarity.

\section{RESULTS}

\section{Regional distribution of NMDA2A/B, GluR6/7, and KA-2 subunits as determined by Western blotting}

As an initial characterization of the glutamate receptor subunit antisera, we examined the regional distribution of NMDAR2A/B, GluR6/7, and KA-2 subunit protein. Similar analyses of NMDAR1, GluR1, GluR2, and GluR4 subunit protein have been reported recently (Fitzgerald et al., 1995). Immunoblot analysis of NMDAR2A/B and GluR6/7 subunits in SDS extracts of brain shows the labeling of single major immunoreactive bands with $M_{\mathrm{r}}$ 150 and $116 \mathrm{kDa}$, respectively (Fig. 1). Major immunoreactive bands for the KA-2 subunit were observed in the $130-150 \mathrm{kDa}$ range. These bands were specifically removed when the antiserum was preabsorbed with the KA-2 antigen peptide (data not shown). NMDAR2A/B and GluR6/7 subunits displayed similar distribution patterns, with only a few notable differences. High levels of these proteins were observed in the striatum, cortex, amygdala, lateral septum, hippocampus, and NAc, with lower levels in the substantia nigra and pons/medulla. However, NMDAR2A/B levels in the cerebellum and hypothalamus were considerably lower compared with other brain regions than the GluR6/7 subunit. In contrast, KA-2 exhibited a more uneven distribution in brain, with very low levels in the VTA and substantia nigra. Therefore, KA-2 levels in DA cell body regions (VTA and substantia nigra) were not examined for potential regulation by drugs of abuse or stress in the present study. We also did not study GluR4, which is present in central DA regions at barely detectable levels (Martin et al., 1993; Fitzgerald et al., 1995).

\section{Effects of repeated cocaine treatment on glutamate receptor subunit immunoreactivity}

As an initial assessment of cocaine's influence on glutamate receptor subunit expression, rats were treated twice daily with cocaine for 2 weeks (15 mg/kg, i.p.), and the levels of NMDAR1, GluR1, and GluR2 subunit protein were examined in the nuclei and terminal fields of the nigrostriatal and mesolimbic DA pathways. We observed significant elevations in GluR1 and NMDAR1 subunit levels in the VTA (Figs. 2, 3). Although this twice daily cocaine treatment paradigm results in some sensitization, greater degrees of sensitization often are observed with longer interdose intervals (see Kalivas and Stewart, 1991). We therefore tested rats following a different dosing paradigm $(20 \mathrm{mg} / \mathrm{kg}$, i.p., daily for 1 week). As observed with the 2 week paradigm, this dosing schedule also increased GluR1 and NMDAR1 levels in the VTA. In contrast, these effects were not observed in rats treated with only a single dose of cocaine $(20 \mathrm{mg} / \mathrm{kg}$, i.p.). These changes also were subunit-specific, because GluR2 levels were not modified after any of the three cocaine treatments used ( $1 \mathrm{~d}, 1$ week, 2 weeks), nor were NMDAR2A/B and GluR6/7 levels modified following the 1 week cocaine protocol (Fig. 2). In contrast to these results in the VTA, the 2 week cocaine regimen had no significant effect on glutamate receptor subunit expression in the other brain regions examined, which included the NAc, striatum, several cortical regions, substantia nigra, and hippocampus (Table 1).

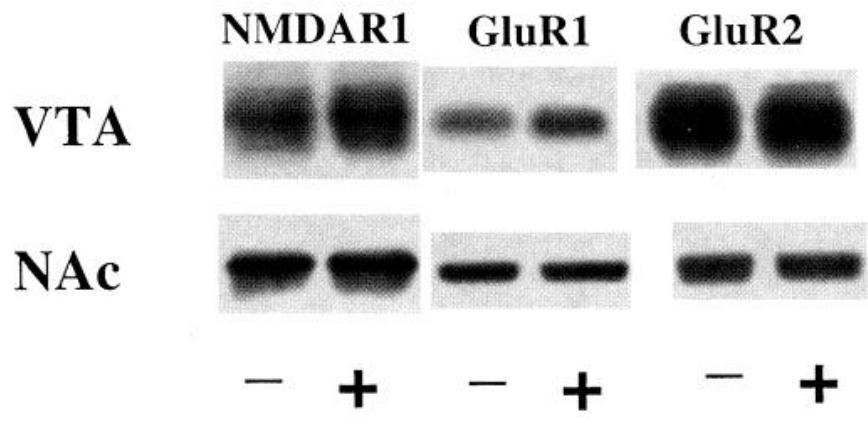

Figure 2. Region- and subunit-specific regulation of glutamate receptor subunit immunoreactivity by repeated ( 2 week) cocaine treatment. Crude homogenates (containing 15-40 $\mu \mathrm{g}$ of protein) were subjected to SDSPAGE and immunoblotting, as described in Materials and Methods. The 2 week ( $15 \mathrm{mg} / \mathrm{kg}$, i.p., twice daily) treatment with cocaine significantly ( ${ }^{*} p$ $<0.05$, unpaired $t$ tests) increased NMDAR1 and GluR1 subunit levels in the VTA but not the NAc or any other region examined (see Table 1). Refer to Table 1 and Figure 3 for a quantitative presentation of the data. 


\section{Regulation of glutamate receptor subunits in the VTA by cocaine}

Figure 3. Regulation of glutamate receptor subunit levels in the VTA by acute $(20 \mathrm{mg} /$ $\mathrm{kg}$, i.p., once) or repeated $(20 \mathrm{mg} / \mathrm{kg}$, i.p., once daily for 1 week; $15 \mathrm{mg} / \mathrm{kg}$, i.p., twice daily for 2 weeks) treatments with cocaine. Rats were used $16 \mathrm{hr}$ after their last injection. Data are derived from 7-12 individual determinations (rats)/group and are expressed as a percentage of control levels $( \pm \mathrm{SEM})$. Both of the repeated cocaine paradigms significantly $\left({ }^{*} p<0.05\right.$, unpaircd $t$ tests) increased NMDAR 1 and GluR1 subunit levels in the VTA.

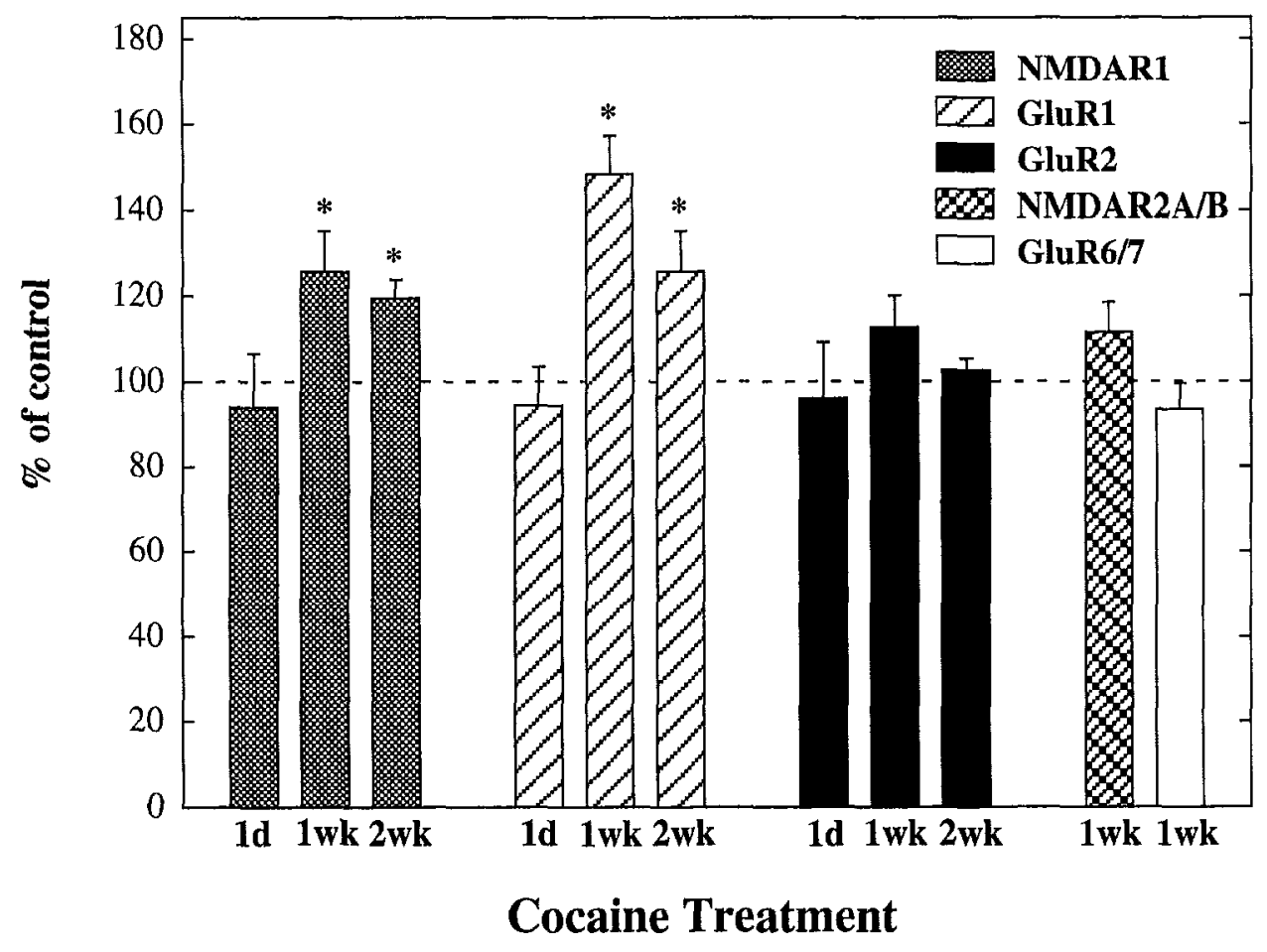

Based on the electrophysiological evidence that alterations in glutamate receptor responsiveness occur in NAc neurons after shorter, once-a-day cocaine exposures (White et al., 1995), we also examined the levels of glutamate receptor subunits in this region following the 1 week cocaine treatment paradigm. However, as with the 2 week paradigm, none of the subunits examined (NMDAR1, GluR1, GluR2, NMDAR2A/B, GluR6/7, or KA-2) was regulated in the NAc (data not shown).

\section{Pharmacological specificity of glutamate receptor regulation in the VTA}

Because cocaine has mixed pharmacological properties (e.g., DA, serotonin, and norepinephrine reuptake blockade), we next examined whether selective noradrenergic (desipramine, $15 \mathrm{mg} / \mathrm{kg}$, i.p., 1 week) or serotonergic (sertraline, $10 \mathrm{mg} / \mathrm{kg}$, i.p., 1 week) reuptake blockers, which lack reinforcing and sensitizing properties, could mimic the effect of cocaine on glutamate receptor subunit expression. For further comparison, we also examined whether nonreinforcing antipsychotic drugs (haloperidol: $1 \mathrm{mg} / \mathrm{kg}$, i.p., 1 week or $0.5 \mathrm{mg} \cdot \mathrm{kg}^{-1} \cdot \mathrm{d}^{-1}$, p.o., 3 weeks; raclopride: 2.2

\begin{tabular}{lccr}
\hline $\begin{array}{l}\text { Table 1. Glutamate receptor subunit immunoreactivity after } \\
\text { repeated (2 week) cocaine regimen }\end{array}$ \\
Region & NMLAR] & GluR1 & GluR2 \\
\hline Frontal-parietal cortex & $97 \pm 5$ & $97 \pm 6$ & $109 \pm 7$ \\
Medial prefrontal cortex & $104 \pm 8$ & $103 \pm 7$ & $101 \pm 9$ \\
Posterior cingulate cortex & $100 \pm 6$ & $104 \pm 6$ & $93 \pm 5$ \\
Striatum & $113 \pm 7$ & $98 \pm 10$ & $97 \pm 6$ \\
Nucleus accumbens & $90 \pm 4$ & $101 \pm 2$ & $100 \pm 5$ \\
Hipnocampus & $97+3$ & $110+3$ & $93+5$ \\
Substantia nigra & $90 \pm 4$ & $100 \pm 8$ & $104 \pm 6$
\end{tabular}

Expressed as percentage of control \pm SEM $[n=6-12$ individual determinations (rats)/treatment group]. $\mathrm{mg} \cdot \mathrm{kg}^{-1} \cdot \mathrm{d}^{-1}$, p.o., 4 weeks) would similarly modify glutamate receptors; these paradigms have been shown previously to elicit significant changes in the electrophysiological and biochemical properties of VTA DA neurons (Chiodo and Bunney, 1983) and to regulate glutamate receptor subunit expression in the terminal fields of central DA pathways (Fitzgerald et al., 1995). Unlike cocaine, however, none of these drug treatments produced significant alterations in the levels of GluR1 or NMDAR1 immunoreactivity in the VTA (Fig. 4).

\section{Regulation of glutamate receptor subunit expression by repeated morphine and stress treatments in the VTA}

Because drugs of abuse and stress can elicit common biochemical and physiological effects acutely (e.g., locomotor and mesolimbic DA activation) and chronically (e.g., locomotor cross-sensitization), we next examined whether repeated exposure to morphine or stress would elicit adaptations in glutamate receptor subunit levels similar to those seen after repeated cocaine exposure. Because the effects of cocaine on glutamate receptor subunit levels were apparently restricted to the VTA, all experiments involving morphine and stress focuscd on this particular brain region. For the morphine experiments, two different dosing paradigms were used. Continuous morphine administration was accomplished by daily subcutaneous pellet implantation for $5 \mathrm{~d}$. Another group of rats received intermittent morphine injections, with escalating doses given subcutaneously over a $10 \mathrm{~d}$ period (see Materials and Methods). As shown in Figure 5, rats treated intermittently with morphine, but not those treated with morphine pellets, displayed a significant increase in levels of GluR1 in the VTA. Furthermore, as observed after cocaine treatment, these alterations in GluR1 levels did not extend to a contiguous and related region, the substantia nigra (data not shown). GluR2 levels were not changed by either paradigm. There was, however, 
Pharmacological analysis of GluR regulation in the VTA

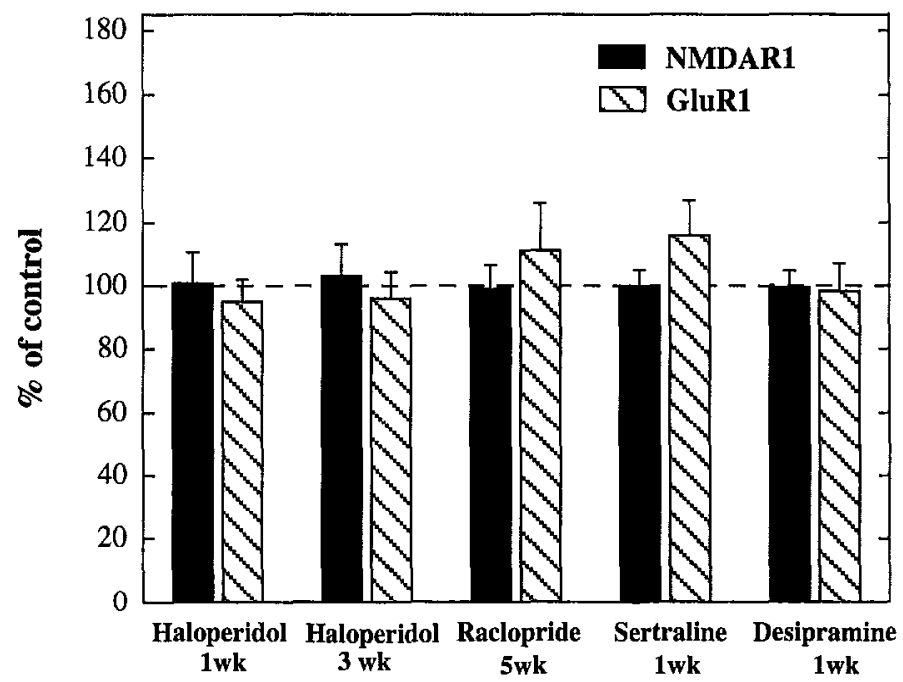

Figure 4. Drugs that lack reinforcing and locomotor-sensitizing properties do not regulate glutamate receptor subunit levels in the VTA. Rats were treated with haloperidol $(1 \mathrm{mg} / \mathrm{kg}$, i.p., daily for 1 week; 0.5 $\mathrm{mg} \cdot \mathrm{kg}^{-1} \cdot \mathrm{d}^{-1}$, p.o., 3 weeks $)$, raclopride $(2.2 \mathrm{mg} / \mathrm{kg}$, p.o., $34 \mathrm{~d})$, sertraline $(10 \mathrm{mg} / \mathrm{kg}$, i.p., daily for 1 week), or desipramine $(15 \mathrm{mg} / \mathrm{kg}$, i.p., daily for 1 week). SDS extracts prepared from VTA samples were subjected to SDS-PAGE and immunoblotting procedures. Data are derived from seven individual determinations (rats)/group and are expressed as percentage of control levels ( \pm SEM)

a tendency for increased levels of NMDAR1 with both paradigms, although this effect was small and did not achieve statistical significance.

Next, rats were exposed to repeated restraint stress or "unpredictable" stress for $10 \mathrm{~d}$ (see Materials and Methods for details), and levels of glutamate receptor subunits were measured the day after the last stressor. As depicted in Figure 6, repeated restraint stress significantly increased GluR1 levels in the VTA, whereas repeated unpredictable stress increased both NMDAR1 and GluR1 levels in this region. Unpredictable stress is considered to be a more rigorous treatment than restraint stress: the former is associated with less habituation, i.e., greater changes in the glucocorticoid axis, than the latter (Sapolsky et al., 1984; Willner, 1984, 1991). In contrast to GluR1 and NMDAR1, GluR2 levels remained unchanged after the two repeated stress paradigms.

\section{DISCUSSION}

The results of the present study demonstrate that repeated exposure to drugs of abuse or to stress upregulates specific glutamate receptor subunits in the VTA. These data raise the possibility that regulation of glutamate receptor expression represents a common molecular adaptation in the mesolimbic D $\Lambda$ system that underlies some of the long-term functional effects of these treatments. Furthermore, these data highlight the plasticity of glutamate receptor expression by treatments that influence central DA function, as shown recently for antipsychotic drugs (Fitzgerald et al., 1995).

A major finding of the present study was that repeated, but not acute, treatment with cocaine upregulated GluR1 and NMDAR1 subunit levels in the VTA, with no effect seen on levels of GluR2, GluR6/7, or NMDAR2A/B subunits. These increases were not observed in other regions of the mesolimbic and nigrostriatal DA
GluR regulation in the $V T A$ by repeated morphine

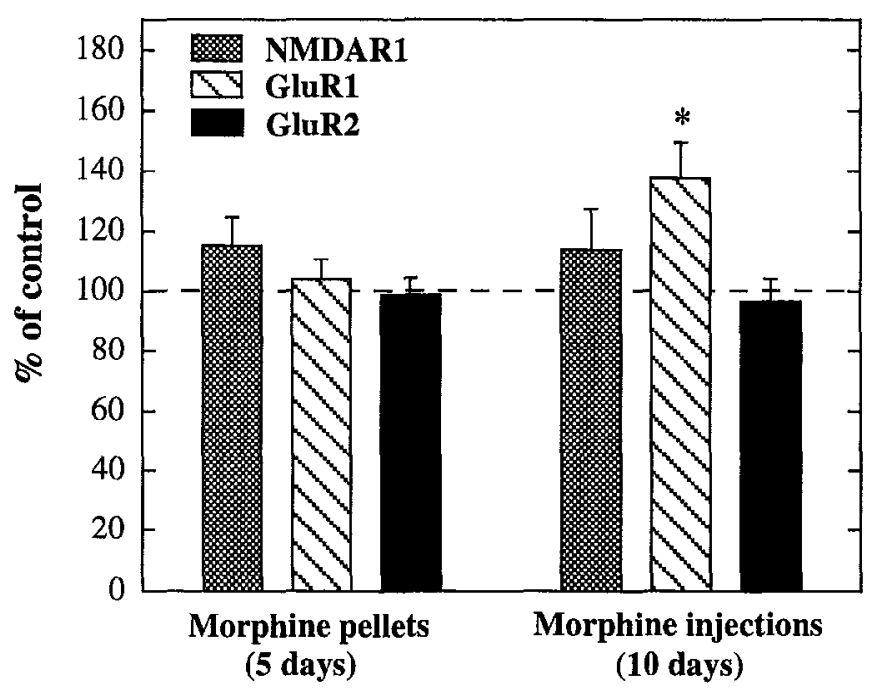

Figure 5. Regulation of glutamate receptor subunit levels in the VTA by chronic morphine treatment. Rats were implanted subcutaneously with pellets (containing $75 \mathrm{mg}$ of morphine base) daily for $5 \mathrm{~d}$ or injected twice daily with an escalating dosing paradigm (see Materials and Methods for details) for $10 \mathrm{~d}$. Data are derived from six individual determinations (rats)/group and are expressed as percentage of control levels ( \pm SEM). The injection, but not the pellet, regimen significantly increased $\left({ }^{*} p<\right.$ 0.05 , unpaired $t$ tests) GluR1 levels in the VTA.

systems, including the substantia nigra. In contrast to cocaine, repeated treatment with psychotropic agents (desipramine, sertraline, haloperidol, or raclopride) that lack reinforcing or sensitizing properties did not upregulate GluR1 or NMDAR1 in the VTA. Similar observations were made with morphine, except that receptor regulation varied with the paradigm of drug administra-

GluR regulation in the VTA by repeated stress

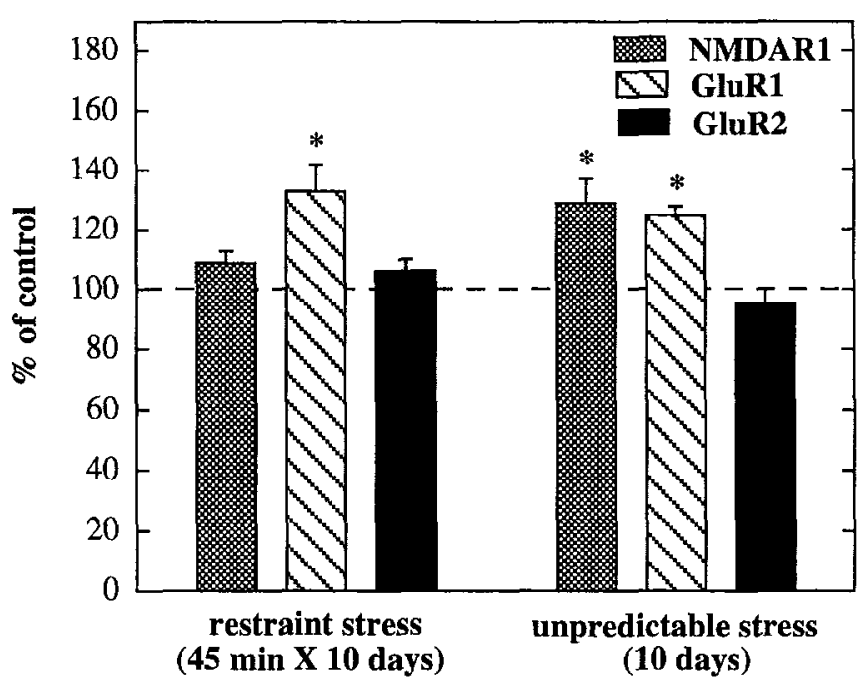

Figure 6. Regulation of glutamate receptor subunit levels in the VTA by repeated restraint stress or unpredictable stress paradigms. Rats were exposed to stress daily for $10 \mathrm{~d}$ (see Materials and Methods for details). Data are derived from six individual determinations (rats)/group and are expressed as percentage of control levels ( \pm SEM). Restraint stress significantly increased ( ${ }^{*} p<0.05$, unpaired $t$ tests) GluR1 levels in the VTA, whercas unpredictable stress increased both GluR1 and NMDAR1 levels in this region. 
tion used. Although morphine delivered continuously via subcutaneous pellet implantation had no influence on glutaniate receptor levels, morphine delivered intermittently by subcutaneous injections of escalating drug doses significantly elevated GluR1 levels in the VTA. This observation is interesting given that the former schedule elicits profound tolerance and dependence (Blasig et al., 1973; Aghajanian, 1978; Rasmussen et al., 1990), whereas the latter schedule is most associated with sensitization (Acquas and Di Chiara, 1992; Spanagel et al., 1993). Increased levels of GluR1 and NMDAR1, but not GluR2, have also been observed recently in the VTA after chronic cthanol cxposure (Ortiz et al., 1995a).

In addition to drugs of abuse, we examined the effects of repeated stress exposure on glutamate receptor subunit levels in the VTA. Both restraint and unpredictable stress upregulated GluR1 levels in this brain region. Unpredictable stress also upregulated NMDAR1 levels. These data underscore the significant interactions among drugs of abuse and stress that occur at the level of the mesolimbic DA pathway. The mesolimbic DA pathway is activated acutely by most drugs of abuse (including cocaine and other stimulants, morphine, and ethanol) as well as by stress. This probably accounts for the increased locomotion observed after acute administration. Repeated treatment with these drugs of abuse or stress can elicit locomotor sensitization, as well as sensitized activation of the mesolimbic DA system, and most of these treatments have been shown to exhibit cross-sensitization with one another. For example, previous exposure to opiates or stimulants can sensitize animals to the locomotor-activating effects of the other drug as well as to stress (Vezina and Stewart, 1990; Kalivas and Stewart, 1991; Cunningham and Kelley, 1992; Hamamura and Fibiger, 1993; Sorg and Kalivas, 1993). Crosssensitization with ethanol has also been reported (Fahlke et al., 1994). Furthermore, previous exposure to stress can enhance or sensitize an animal to the acquisition of drug self-administration behavior (Piazza et al., 1991; Goeders and Guerin, 1994; Shaham and Stewart, 1994; Shaham et al., 1994), suggesting that stress regulates the reinforcing properties of drugs of abuse in addition to their locomotor-activating properties. These behavioral and neurochemical phenomena of cross-sensitization are consistent with the existence of common molecular adaptations underlying these phenomena, such as the common upregulation of GluR1 and NMDAR1 observed in the present study.

Given the structural similarity between the mesolimbic and nigrostriatal DA systems, it is striking that cocaine and the other treatments regulated glutamate receptor expression in the VTA only, although ethanol increased GluR1 levels in both the VTA and substantia nigra (Ortiz et al., 1995a). It is possible that the observed regional specificity resulted in part from the VTA and substantia nigra dissections used, because medial aspects of the substantia nigra were excluded from the nigral dissections (see Materials and Methods) to ensure dissociation between the two structures. In situ hybridization analysis possibly could provide further insight into this question. Another possibility is that differential regulation of glutamate receptor subunits in the VTA and substantia nigra reflects functional differences between mesolimbic and nigrostriatal DA neurons and their afferent connections. Indeed, the two types of DA neurons are known to respond differently to a number of drug treatments (Chiodo and Bunney, 1983; Carlsson and Carlsson, 1990; Nestler et al., 1993). Moreover, although both the mesolimbic and nigrostriatal DA systems contribute to locomotor sensitization to stimulants, the mesolimbic DA system is implicated more in the motivational and rein- forcing aspects of drug action, whereas the nigrostriatal DA system is implicated more in the locomotor activation and stereotypy produced by drug exposure (Karler et al., 1989; Wise, 1990; Kalivas and Stewart, 1991; Koob, 1992; Pinheiro-Carrera et al., 1995; Self and Nestler, 1995).

The important role of the glutamate system in the regulation of mesolimbic DA function is well documented. Glutamate, derived largely from projections of the medial prefrontal cortex and other brain regions (Zhang et al., 1992), likely activates VTA DA neurons via all three major classes of ionotropic glutamate receptors (NMDA, AMPA, and kainate). For example, NMDA or glutamate applied to the VTA increases the firing rate and burst activity of dopaminergic neurons and increases DA release in the NAc (Johnson et al., 1992; Suaud-Chagny et al., 1992). However, higher doses of these agonists can have the opposite effect, which has been attributed to depolarization blockade. This is a phenomenon in which excessive stimulation of these cells raises their membrane potential to a point where voltage-dependent $\mathrm{Na}^{+}$ channels inactivate; this, in turn, leads to a profound reduction in mesolimbic DA activity (Chiodo and Bunney, 1983).

Previous work has implicated glutamatergic neurotransmission in the adaptability of the mesolimbic DA system after long-term exposure to drugs of abuse and stress. AMPA or NMDA antagonists, given systemically or applied directly to the VTA, have been shown to block the development of locomotor sensitization (Schenk et al., 1993; Karler et al., 1991; Wolf and Jeziorski, 1993). NMDA antagonism also blocks the electrophysiological changes in mesolimbic DA function that are associated with repeated stimulant exposure. For example, MK-801 blocks psychostimulant-induced DA autoreceptor subsensitivity in VTA DA neurons and postsynaptic DA $D_{1}$ receptor supersensitivity in NAc neurons (Wolf et al., 1994). Furthermore, a recent electrophysiological study shows that VTA DA neurons in rats treated repeatedly with cocaine or amphetamine show an enhanced responsiveness to glutamate and enter depolarization blockade at significantly lower iontophoretic currents (White et al., 1995). It has been hypothesized that this effect of glutamate preferentially involves non-NMDA receptors (e.g., AMPA receptors). The cocaine-induced increases in specific glutamate receptor subunits observed in the present study could account for the enhanced responsiveness to glutamate observed electrophysiologically, particularly GluR1-a major component of AMPA receptors. Increased vulnerability for depolarization blockade of VTA DA neurons also has been observed after chronic alcohol exposure (Diana et al., 1993; Shen and Chiodo, 1993), and increases in GluR1 and NMDAR1 similarly could mediate this phenomenon as well (Ortiz et al., 1995a). Interestingly, chronic administration of haloperidol and raclopride, under conditions known to produce depolarization blockade of VTA DA neurons (Chiodo and Bunney, 1983), failed to alter glutamate receptor subunit expression in this brain region. These findings suggest that different molecular mechanisms are responsible for the increased vulnerability for depolarization blockade induced by drugs of abuse on the one hand and the frank depolarization blockade induced by antipsychotics drugs on the other. This is not surprising, because the two classes of drugs produce very different effects on mesolimbic DA function and behavior. It also remains unclear how changes in an individual glutamate receptor subunit are translated electrophysiologically and which cell type (e.g., DA or non-DA) in the VTA exhibits this regulation. With regard to the latter point, GluR1 has been reported to be enriched in dopaminergic cells within the VTA and substantia nigra (Martin et al., 1993).

In contrast to VTA DA neurons, it also was found by White et al. (1995) that NAc neurons were less sensitive to the excitatory 


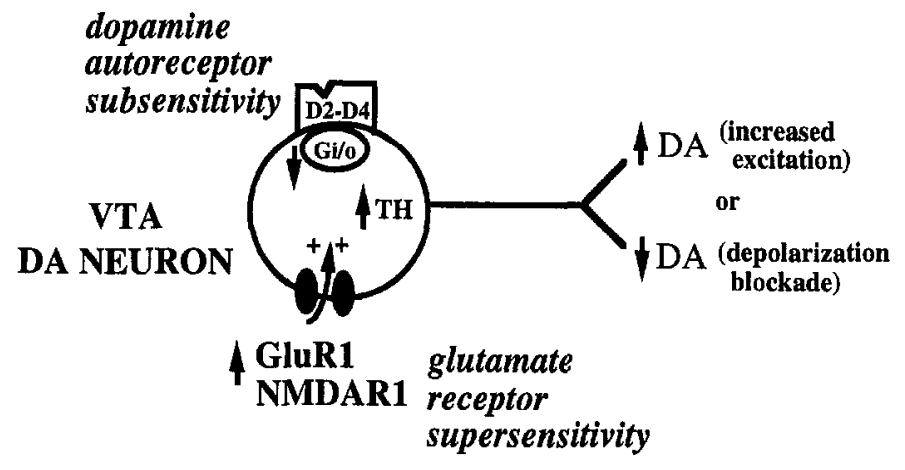

Figure 7. Hypothetical schematic depiction of biochemical and functional adaptations in the VTA after repeated treatment with cocaine and, perhaps, other drugs of abuse or stress. In the drug-treated state, elevated levels of TH, which would confer an enhanced capacity for DA synthesis, may be associated with an increased activational state of VTA DA neurons. Such an increased activational state of these neurons may result, at least in part, from DA autoreceptor subsensitivity and glutamate receptor supersensitivity. Decreased levels of inhibitory G-proteins $\left(G_{i} / G_{o}\right)$ and increased levels of glutamate receptor subunits (GluR1/NMDAR1) may represent the biochemical underpinnings of these electrophysiological observations, respectively. Excessive excitation of the neurons may result, however, in depolarization inactivation of mesolimbic impulse flow, thereby reducing DA release in the NAc and other mesolimbic target regions. This latter scenario may be particularly relevant to the reduced neuronal firing of VTA DA neurons, reduced mesolimbic DA release, and aversive behavioral features observed during early phases of withdrawal from some drugs of ahuse.

effects of glutamate. In the present study, we did not observe significant changes in levels of specific glutamate receptor subunits (NMDAR1, NMDAR2A/B, GluR1, GluR2, or GluR6/7) using a very similar cocaine-dosing paradigm. This suggests that there are adaptations in subunits not examined in the present study (e.g., the AMPA GluR3 subunit) or, perhaps, that posttranslational changes (e.g., phosphorylation) in receptor function occur independently of subunit protein levels. Alternatively, the reported glutamate subsensitivity in the NAc could be an indirect manifestation of perturbations in other neurotransmitter systems (for discussion, see White et al., 1995).

Increased levels of GluR1 (and NMDAR1) in the VTA by cocaine, morphine, ethanol (Ortiz et al., 1995a), and stress treatments represent additional molecular compensations that presumably underlie some common functional effects of these treatments in the mesolimbic DA pathway (Fig. 7) (Nestler et al., 1993). Although relating molecular phenomena to neural function can be daunting, some progress has been made. For example, these drugs of abuse and stress each increase tyrosine hydroxylase (TH) expression in the VTA (Beitner-Johnson and Nestler, 1990; Hurd et al., 1992; Sorg et al., 1993; Vrana et al., 1993; Ortiz et al., 1995a; Ortiz et al., 1995b). This increase would be expected to augment the maximal capacity of VTA DA neurons to synthesize DA. Indeed, the increased levels of TH in the VTA do correlate temporally with the emergence of locomotor sensitization to cocaine (Sorg et al., 1993). Moreover, increased TH expression often is proportional to the state of activation of catecholaminergic cells. This view is based on studies of central and peripheral noradrenergic neurons, adrenal medullary chromaffin cells, and cultured cells of neural crest origin (for references, see Guitart et al., 1990). Increases in the number and frequency of spontaneously active DA neurons after chronic stimulant and morphine exposure (Henry et al., 1989) (F. White, personal communica- tion), and an increased sensitivity for depolarization blockade after chronic stimulant (White et al., 1995) and ethanol (Diana et al., 1993; Shen and Chiodo, 1993) exposure, have been reported. Upregulated GluR1 and NMDAR1 subunit levels by drugs of abuse and stress may contribute to such an increased excitability of VTA DA neurons. Decreased levels of inhibitory $G_{i}$ and $G_{o}$ proteins in the VTA after repeated cocaine treatment (Nestler et al., 1989; Striplin and Kalivas, 1992) could account for the DA autoreceptor subsensitivity observed electrophysiologically (Henry et al., 1989) and neurochemically (Pierce et al., 1995) and also could contribute to increased neuronal excitability. Excessive excitation, followed by depolarization blockade, however, actually would have the opposite functional effect by reducing mesolimbic DA activity. Depolarization blockade would be expected to be more severe between drug exposures and could contribute to the reductions in extracellular DA levels seen in the NAc during short-term withdrawal from stimulants, opiates, and alcohol (Acquas et al., 1991; Rossetti et al., 1992; Diana et al., 1993). These reductions in DA have been related to the aversive features of drug withdrawal and could contribute to drug craving (Dackis and Gold, 1985; Markou and Koob, 1991; Weiss et al., 1992). Subsequent exposure to the drug or stress (as in a sensitization paradigm), then, could transiently relieve the depolarization blockade and thereby increase dopaminergic transmission to the NAc. Such relief of depolarization blockade could occur via stimulation of hyperpolarizing receptors (e.g., DA autoreceptors or GABA receptors) located on VTA DA neurons or, perhaps, via reduction of glutamatergic inputs to the VTA.

In summary, repeated exposure to cocaine, morphine, ethanol, or stress increases GluR1 and, in most cases, NMDAR1 subunit levels in the VTA. Several drugs that lack sensitizing or reinforcing properties do not elicit these alterations. Although significant work remains to relate causally these adaptations to common neural mechanisms underlying drug addiction or locomotor sensitization, these data indicate that adaptation in glutamate receptor subunit expression may be an important and novel mechanism by which drugs of abuse and stress exert long-term effects on mesolimbic DA function.

\section{REFERENCES}

Acquas E, Carboni E, Di Chiara G (1991) Profound depression of mesolimbic dopamine release after morphine withdrawal in dependent rats. Eur J Pharmacol 193:133-134.

Acquas E, Di Chiara G (1992) Depression of mesolimbic dopamine transmission and sensitization to morphine during opiate abstinence. $J$ Neurochem 58:1620-1625.

Aghajanian GK (1978) Tolerance of locus coeruleus neurons to morphine and suppression of withdrawal response by clonidine. Nature 267:186-188.

Beitner-Johnson D, Nestler EJ (1990) Morphine and cocaine exert common chronic actions on tyrosine hydroxylase in dopaminergic brain reward regions. J Neurochem 57:344-347.

Blasig J, Herz A, Reinhold K, Zieglgansberger S (1973) Development of physical dependence on morphine in respect to time and dosage and quantification of the precipitated withdrawal syndrome in rats. Psychopharmacologia 33:19-38.

Carlsson M, Carlsson A (1990) Interactions between glutamatergic and monoaminergic systems in the basal ganglia-implications for schizophrenia and Parkinson's disease. Trends Neurosci 13:272-276.

Chen I, Paredes W, I. J, Smithe D, I nwinson I, Gardner FI. (1990) $\Delta^{9}$-tetrahydrocannabinol produces naloxone-blockable enhancement of presynaptic basal dopamine efflux in nucleus accumbens of conscious, freely-moving rats as measured by intracerebral microdialysis. Psychopharmacology 102:156-162.

Chiodo LA, Bunney BS (1983) Typical and atypical neuroleptics: differential activity of chronic administration on the activity of A9 and A10 midbrain dopaminergic neurons. J Neurosci 3:1607-1619. 
Collingridge GL, Singer W (1990) Excitatory amino acid receptors and synaptic plasticity. Trends Pharmacol Sci 11:290-296.

Cunningham ST, Kelley AE (1993) Evidence for opiate-dopamine crosssensitization in the nucleus accumbens: studies of conditional reward. Brain Res Bull 29:675-680.

Dackis CA, Gold MS (1985) New concepts in cocaine addiction: the dopamine depletion hypothesis. Neurosci Biobehav Rev 9:469-477.

Diana M, Pistis M, Carboni S, Gessa GL, Rossetti ZL (1993) Profound decrement of mesolimbic dopaminergic neuronal activity during ethanol withdrawal syndrome in rats: electrophysiological and biochemical evidence. Proc Natl Acad Sci USA 90:7966-7969.

Di Chiara G, Imperato A (1988) Drugs abused by humans preferentially increase synaptic dopamine concentrations in the mesolimbic system of freely moving rats. Proc Natl Acad Sci USA 85:5274-5278.

Fahlke C, Hansen S, Engel JA, Hard E (1994) Effects of ventral striatal 6-OHDA lesions or amphetamine sensitization on ethanol consumption in the rat. Pharmacol Biochem Behav 47:345-349.

Fitzgerald LW, Nestler EJ (1995) Cocaine regulation of signal transduction pathways. In: Neurobiology of cocaine: molecular and cellular aspects (Hammer R, ed), pp. 219-240. Boca Raton, FL: CRC.

Fitzgerald LW, Deutch AY, Gasic G, Heinemann SF, Nestler EJ (1995) Regulation of cortical and subcortical glutamate receptor subunit expression by antipsychotic drugs. J Neurosci 15:2453-2461.

Goeders NE, Guerin GF (1994) Non-contingent electric footshock facilitates the acquisition of intravenous cocaine self-administration in rats, Psychopharmacology 114:63-70.

Guitart X, Hayward M, Nisenbaum LK, Beitner DB, Haycock JW, Nestler EJ (1990) Identification of MARPP-58, a morphine- and cyclic AMPregulated phosphoprotein of $58 \mathrm{kDa}$, as tyrosine hydroxylase: evidence for regulation of ts expression by chronic morphine in the rat locus coeruleus. J Neurosci 10:2635-2645.

Hamamura T, Fibiger HC (1993) Enhanced stress-induced dopamine release in the prefrontal cortex of amphetamine-sensitized rats. Eur $\mathbf{J}$ Pharmacol 237:65-71.

Henry DJ, Greene MA, White FJ (1989) Electrophysiological effects of cocaine in the mesoaccumbens dopamine system: repeated administration. J Pharmacol Exp Ther 251:833-839.

Henry DJ, White FJ (1991) Repeated cocaine administration causes persistent enhancement of D1 dopamine receptor sensitivity within the nucleus accumbens. J Pharmacol Exp Ther 258:882-890.

Hollmann M, Heinemann S (1994) Cloned glutamate receptors. Annu Rev Neurosci 17:31-108.

Hurd YL, Linefors N, Brodin E, Brené S, Persson $\mathrm{H}$, Ungerstedt U, Hökfelt $T$ (1992) Amphetamine regulation of mesolimbic dopamine/ cholecystokinin neurotransmission. Brain Res 578:317-326.

Johnson SW, Seutin V, North RA (1992) Burst firing in dopamine neurons induced by $N$-methyl-D-aspartate: role of electrogenic pump. Science 258:665-667.

Kalivas PW (1993) Neurotransmitter regulation of dopamine neurons in the ventral tegmental area. Brain Res Rev 18:75-113.

Kalivas PW, Duffy P (1990) Effects of acute and daily cocaine treatments on extracellular dopamine in the nucleus accumbens. Synapse 5:48-58.

Kalivas PW, Stewart J (1991) Dopamine transmission in the initiation and expression of drug- and stress-induced sensitization of motor activity. Brain Res Rev 16:223-244.

Karler R, Calder LD, Chaudhry IA, Turkanis SA (1989) Blockade of reverses tolerance to cocaine and amphetamine by MK-801. Life Sci 45:599-606.

Karler R, Chaudhry IA, Calder LD, Turkanis SA (1991) DNQX blockade of amphetamine behavioral sensitization. Brain Res 552:295-300.

Koob GF (1992) Drugs of abuse: anatomy, pharmacology and function of reward pathways. Trends Pharmacol Sci 13:177-184.

Kuhar MJ, Ritz MC, Boja JW (1991) The dopamine hypothesis of the reinforcing propertics of cocainc. Trends Ncurosci 14:299-302.

Markou A, Koob GF (1991) Post-cocaine anhedonia: an animal model of cocaine withdrawal. Neuropsychopharmacology 4:17-26.

Martin L, Blackstone CD, Levey AI, Huganir RL, Price DL (1993) AMPA glutamate receptor subunits are differentially distributed in rat brain. Neuroscience 53:327-358.

Monaghan DT, Bridges RJ, Cotman CW (1989) The excitatory amino acid receptors: their classes, pharmacology, and distinct properties in the function of the central nervous system. Annu Rev Pharmacol Toxicol 29:365-402.
Morinobu S, Nibuya M, Duman R (1995) Chronic antidepressant treatment down-regulates the induction of $c$-fos $m R N A$ in response to acute stress in rat frontal cortex. Neuropsychopharmacology 12:221-228.

Nakanishi S (1992) Molecular diversity of glutamate receptors and implications for brain function. Science 597-603.

Nestler EJ, Terwilliger RZ, Walker JR, Sevarino KA, Duman RS (1989) Chronic cocaine treatment decreases levels of the G-protein subunits $G_{i \alpha}$ and $G_{o \alpha}$ in discrete regions of the rat brain. $J$ Neurochem 55:1079-1082.

Nestler EJ, Hope BT, Widnell KL (1993) Drug addiction: a model for the molecular basis of neural plasticity. Neuron 11:995-1006.

Ortiz J, Fitzgerald LW, Charlton M, Lane S, Trevisan L, Guitart X, Shoemaker W, Duman RS, Nestler EJ (1995a) Biochemical actions of chronic ethanol exposure in the mesolimbic dopamine system. Synapse, in press.

Ortiz J, Fitzgerald LW, Lane S, Terwilliger R, Nestler EJ (1995b) Biochemical effects of repeated stress in the mesolimbic dopamine system. Neuropsychopharmacology, in press.

Paxinos G, Watson CW (1986) The rat brain in stereotaxic coordinates, 2nd ed. Sydney: Academic.

Petralia RS, Y-X Wang, Wenthold RJ (1994) The NMDA receptor subunits NR2A and NR2B show histological and ultrastructural localization patterns similar to those of NR1. J Neurosci 14:6102-6120.

Piazza PV, Maccari S, Deminiere JM, Le Moal M, Mormede P, Simon H (1991) Corticosterone levels determine individual vulnerability to amphetamine self-administration. Proc Natl Acad Sci USA 88:2088-2092.

Pierce RC, Duffy P, Kalivas KW (1995) Sensitization to cocaine and dopamine autoreceptor subsensitivity in the nucleus accumbens. Synapse 20:33-36.

Pinheiro-Carrera M, Tomaz C, Huston JP, Carey RJ (1995) NMDA antagonist effects on the development of L-dopa behavioral sensitization in rats. Behav Neurosci 109:34-42.

Post RM, Rose H (1976) Increasing effects of repetitive cocaine administration in rats. Nature 260:731-734.

Puchalski RB, Louis J-C, Brose N, Traynelis SF, Egebjerg J, Kukekov V, Wenthold RJ, Rogers SW, Lin F, Moran T, Morrison JH, Heinemann SF (1994) Selective RNA cditing and subunit asscmbly of native glutamate receptors. Neuron 13:131-147.

Rasmussen K, Beitner-Johnson DB, Krystal JH, Aghajanian GK, Nestler EJ (1990) Opiate withdrawal and the rat locus coeruleus: behavioral, electrophysiological, and biochemical correlates. J Neurosci 10:2308-2317.

Robinson TE, Jurson PA, Bennett JA, Bentgen KM (1988) Persistent sensitization of dopamine neurotransmission in ventral striatum (nucleus accumbens) produced by prior experience with $(+)$-amphetamine: a microdialysis study in freely moving rats. Brain Res 462:211-222.

Roche KW, Raymond LA, Blackstone C, Huganir RL (1994) Transmembrane topology of the glutamate receptor subunit GluR6. J Biol Chem 269:11679-11682.

Rossetti ZL, Hmaidan Y, Gess GL (1992) Marked inhibition of mesolimbic dopamine release: a common feature of ethanol, morphine, cocaine and amphetamine abstinence in rats. Eur J Pharmacol 221:227-234.

Sapolsky RM, Krey LC, McEwen BS (1984) Stress down-regulates corticosterone receptors in a site-specific manner in the brain. Endocrinology $114: 287-292$.

Schenk S, Valadez A, McNamara C, House DT, Higley D, Bankson MG, Gibbs S, Horger BA (1993) Development and expression of sensitization to cocaine's reinforcing properties: role of NMDA receptors. Psychopharmacology 111:332-338.

Segal DS, Kuczenski (1992) In vivo microdialysis reveals a diminished amphetamine-induced DA response corresponding to behavioral sensitization produced by repeated amphetamine treatment. Brain Res 571:330-337.

Self DW, Nestler EJ (1995) Molecular mechanisms of drug reinforcemont and addiction. Annu Rcv Neurosci 18:463-495.

Seutin V, Johnson SW, North RA (1994) Effect of dopamine and baclofen on $N$-methyl-D-aspartate-induced burst firing in rat ventral tegmental neurons. Neurosci 58:201-206.

Shaham Y, Stewart J (1994) Exposure to mild stress enhances the reinforcing efficacy of intravenous heroin self-administration. Psychopharmacology 114:523-527.

Shaham Y, Alvares K, Nespor SM, Grunberg NE (1994) Effect of stress on oral morphine and fentanyl self-administration in rats. Pharmacol Biochem Behav 41:615-619. 
Shen R-Y, Chiodo LA (1993) Acute withdrawal after repeated ethanol treatment reduces the number of spontaneously active dopaminergic neurons in the ventral tegmental area. Brain Res 622:289-293.

Siegel SJ, Brose N, Janssen WG, Gasic GP, Jahn R, Heinemann SF, Morrison JH (1994) Regional, cellular, and ultrastructural distribution of $N$-methyl-D-aspartate receptor subunit 1 in monkey hippocampus I. Proc Natl Acad Sci USA 91:564-568.

Sorg BA, Kalivas PW (1993) Behavioral sensitization to stress and psychostimulants: role of dopamine and excitatory amino in the mesocorticolimbic system. Semin Neurosci 5:343-350.

Sorg BA, Chen S-Y, Kalivas PW (1993) Time course of tyrosine hydroxylase expression after behavioral sensitization to cocaine. J Pharmacol Exp Ther 266:424-430.

Spanagel R, Almeida OFX, Shippenburg TS (1993) Long-lasting changes in morphine-induced mesolimbic dopamine release after chronic morphine exposure. Synapse 14:243-245.

Striplin CD, Kalivas PW (1992) Correlation between behavioral sensitization to cocaine and $G$ protein ADP-ribosylation in the ventral tegmental area. Brain Res 579:181-186.

Suaud-Chagny MF, Chergui K, Chouvet G, Gonon F (1992) Relationship between dopamine release in the rat nucleus accumbens and the discharge activity of dopaminergic neurons during local in vivo application of amino acids in the ventral tegmental area. Neuroscience 49:63-72.

Terwilliger RZ, Beitner-Johnson D, Sevarino KA, Crain SM, Nestler EJ (1991) A general role for adaptations in G-proteins and the cyclic AMP system in mediating the chronic actions of morphine and cocaine on neuronal function. Brain Res 548:100-110.

Trevisan L, Fitzgerald LW, Brose N, Gasic GP, Heinemann SF, Duman RS, Nestler EJ (1994) Chronic ingestion of ethanol up-regulates NMDAR1 immunoreactivity in rat hippocampus. J Neurochem 62:1635-1638.

Vezina P, Stewart J (1990) Amphetamine administered to the ventral tegnental area but not to the nucleus accumbens sensitizes rats to systemic morphine: lack of conditional effects. Brain Res 516:99-106.

Vrana SL, Vrana KE, Koves TR, Smith JE, Dworkin SI (1993) Chronic cocaine administration increases CNS tyrosine hydroxylase enzyme ac- tivity and mRNA levels and tryptophan hydroxylase enzyme activity levels. J Neurochem 61:2262-2268.

Wang T, French ED (1993a) Electrophysiological evidence for the existence of NMDA and non-NMDA receptors on rat ventral tegmental neurons, Synapse 13:270-277.

Wang T, French ED (1993b) L-Glutamate excitation of A10 dopamine neurons is preferentially mediated by activation of NMDA receptors: extra- and intracellular electrophysiological studies in brain slices. Brain Res 627:299-306.

Weiss F, Markou A, Lorang MT, Koob GF (1992) Basal extracellular levels in the nucleus accumbens are decreased during cocaine withdrawal after unlimited-access self-administration. Brain Res 593:314-318.

Wenthold RJ, Yokotani N, Doi K, Wada K (1992) Immunochemical characterization of the non-NMDA glutamate receptor using subunitspecific antibodies: evidence for hetero-oligomeric structure in rat brain. J Biol Chem 267:501-507.

White FJ, Hu X-T, Zhang X-F, Wolf ME (1995) Repeated administration of cocaine or amphetamine alters neuronal responses to glutamate in the mesoaccumbens dopanine system. J Pharmacol Exp Ther 273:445-454

Willner P (1984) The validity of animal models of depression. Psychopharmacology 83:1-16.

Willner P (1991) Animal models as simulations of depression. Trends Pharmacol Sci 12:131-136.

Wise RA (1990) The role of reward pathways in the development of drug dependence. In: Psychotropic drugs of abuse (Balfour DJK, ed), pp. 23-57. Oxford: Pergamon.

Wolf ME, Jeziorski M (1993) Coadministration of MK-801 with amphetamine, cocaine or morphine prevents rather than transiently masks the development of behavioral sensitization. Brain Res 613:291-294.

Wolf ME, White FJ, Hu X-T (1994) MK-801 prevents alterations in the mesoaccumbens dopamine system associated with behavioral sensitization to amphetamine. J Neurosci 14:1735-1745.

Zhang J, Chiodo LA, Freeman AS (1992) Electrophysiological effects of MK-801 on rat nigrostriatal and mesoaccumbal dopaminergic neurons. Brain Res 590:153-163. 